\title{
APPLICATION OF ADAPTIVE NEURO-FUZZY INFERENCE SYSTEM FOR THE ESTIMATION OF ROUGHNESS COEFFICIENT OF A MEANDERING OPEN-CHANNEL FLOW
}

\author{
S. MOHARANA, K. K. KHATUA \& M. SAHU \\ Department of Civil Engineering, National Institute of Technology, India.
}

\begin{abstract}
An experimental investigation concerning the variation in roughness for meandering channels with flow depths, aspect ratio and sinuosity is presented. Test results revealed that the value of roughness coefficient in terms of Chezy's $C$ increases with increase in aspect ratio and sinuosity. Adaptive neuro-fuzzy-based inference system (ANFIS), an integrated system, a combination of fuzzy logic and neural network is employed to find out the roughness coefficient of a meandering channel. Estimation of roughness coefficient is important for forecasting of discharge because its flexibility to resolve issues supported nonlinearity, randomness and uncertainty of knowledge. In the present work, an ANFIS-based model is developed for the prediction of the roughness coefficient of a meandering channel in terms of Chezy's $C$. Different standard methods to predict this variable are conjointly tested and verified with the laboratory findings as well as global data moreover. By comparing the results with the established standard methods available in the literature, it was observed that traditional methods could not provide satisfactory output at different surface and hydraulic conditions. Statistical error analysis is also carried out in which it was found that ANFIS model performed more accurately giving results with less error than different existing strategies. The analysis shows a high level of accuracy with regard to the ANFIS-based model developed for predicting the Chezy's $C$ especially coefficients of determination are found to be more encouraging.

Keywords: Aspect ratio, flow resistance, fuzzy inference system, meandering channel, sinuosity.
\end{abstract}

\section{INTRODUCTION}

Estimation of roughness coefficients in a natural channel is the fundamental problem in open-channel hydraulics. It involves in itself directly to the entire flow problem ranging from the prediction of flood, water level management, to the protection measures. Although much research has been performed to supplement basic roughness coefficients for a simple open-channel flow [1], less has been done for a meandering channel. According to researchers, the behavior of the flow is surprisingly complex. Consequently, the use of design methods based on straight simple channels is inappropriate when applied to single meandering channels and will result in large errors when estimating the discharge.

There is a tendency with regard to the selection of roughness coefficients as either an arbitrary or an intuitive process. Specific procedures can be used to determine the values for roughness coefficients in channels. Values of the roughness coefficient may be assigned for conditions that exist at the time of a specific flow event, for average conditions over a range in stage, or for anticipated conditions at the time of a future event. The flow behavior of a meandering channel is surprisingly more complex than that of a straight channel as reported by Sellin [2], Shiono et al. [3], Patra and Kar [4], Khatua [5], Patra and Khatua [6] and Khatua et al. [7]. For this reason, it is very difficult to select an appropriate value of roughness coefficient in calculating the sectional mean velocity. The equations [4] proposed by Chezy, Darcy-Weisbach or Manning are used in river hydraulics to compute the mean velocity. To compute the exact discharge in a meandering open-channel flow, the single most influencing important parameter is to select a suitable value of roughness coefficient in terms of Manning's $n$, Chezy's $C$ or Darcy-Weisbach friction factor $f$. The basic approach proposed 
by Cowan [8] was modified by Acrement and Schneider [9]. Waterways experiments were conducted by Army Corps of Engineers [10] in meandering channels at the Station to investigate the conveyance capacity of meandering channel. James [11] suggested a huge energy loss due to bending curvature in a meandering channel. The Soil Conservation Service method developed by USGS, Washington [12] is also used for selecting roughness coefficient values for meandering channels. These are found to be discontinuous at the certain limits of the defined sinuosity ranges with consequent ambiguity. The most sensitive parameter channel roughness of a natural river was calibrated by Parhi et al. [13] and Hameed and Ali [14] in developing a hydraulic model for flood forecasting and flood plain mapping. Maria and DaSilva [15] expressed the friction factor of rough turbulent meandering flows. Shiono et al. [3] reported the effect of bed slope and sinuosity on discharge of meandering channel. On the basis of dimensional analysis, Khatua et al. [7] proposed an equation to predict the roughness coefficient in terms of Chezy's $C$ of a meandering channel.

From the literatures, it is found that reasonable effect of different hydraulic, geometry and surface parameters exists for estimating discharge in meandering channels. This resistance value is assigned an average value. For the proper estimation of discharge in an open-channel section, selection of a suitable value of Chezy's $C$ is an important aspect that needs to be addressed properly. Under steady and uniform flow conditions, to compute the section mean discharge carried by a channel section is calculated with the help of Chezy's equation as

$$
Q=C A \sqrt{R S}
$$

where $Q$ is the section mean discharge of the channel, $R$ the hydraulic mean radius of the channel section, $A$ the cross-sectional area of the channel, $S$ the energy gradient slope of the channel and $C$ the Chezy's channel coefficient. An easily implementable technique such as adaptive neuro-fuzzy inference system (ANFIS) can be adapted to develop a model for prediction of the Chezy's $C$ of a meandering channel. This will be useful in accurate evaluation of discharge to solve many practical problems and to study the mechanism of flow in a better way. The results of the present model are compared well with other established methods.

\section{DETERMINATION OF ROUGHNESS VALUE IN MEANDERING OPEN-CHANNEL FLOW}

Presently, rapid development in intelligence computing not only lessens the tedious effort of experimentation but also eliminates tedious computations. Investigators adopted used back propagation algorithm of artificial neural network (ANN) for the prediction of roughness in a meandering openchannel flow [16]. ANFIS has been adopted in a variety of fields for accurate prediction of responses in situations where solution is imprecise and uncertain. Nowadays, discharge can be forecasted using the easily ANFIS techniques. When a relationship between input and output is difficult to establish using mathematical, analytical and numerical methods and it becomes cumbersome and time consuming, an easily implementable technique such as ANFIS can be adopted. Thus, an ANFIS model has been proposed in this work to predict a resistance factor in meandering open-channel flow. These ANFIS results are found to be quite comparable to that of the observed values of the published data.

\section{EXPERIMENTAL SETUP AND PROCEDURE}

Experiments on meandering channels of different sinuosity and flow conditions were conducted by utilizing the facility in the Fluid Mechanics and Hydraulics Engineering Laboratory of the Civil Engineering Department, at the National Institute of Technology, Rourkela, India. Inside the existing 
tilting flumes, the meandering channels are fabricated for studying the influence of sinuosity in predicting roughness coefficients and stage-discharge relationships of a meandering channel. Here, the channels of trapezoidal in cross-section were casted using 6/10-mm thick Perspex sheets. The provision of tilting arrangements of the flumes has provided different longitudinal slopes for the experimental runs. The photograph of one of the run of a meandering channel with measuring equipments taken from the downstream side is now shown in Photo 1.

All the runs of the experiments are carried out by a re-circulating water system. Water is lifted from underground sump to the overhead tank with the help of some parallel pump arrangement. From this overhead tank, water is led to the stilling tank that is located at the upstream of the channel. For reducing the turbulence of incoming water, a series of baffle walls are provided in between the stilling tank and channels. Water is allowed to flow through the channel and then passed through the tail gate of channel and finally collected in a masonry volumetric tank from where the flow it is turned back to the underground sump. From the sump, again water is pumped back to the overhead tank; thus, the setting covers a complete re-circulating system of water supply to the experimental channel. The tilting type of tailgate at the downstream end is there to establish uniform flow of water through the channel. Each experimental runs of the channel are carried out by maintaining the water surface slope parallel to the valley slope to achieve the steady and uniform flow conditions. This is explained in a better way with a sketch diagram (Fig. 1).

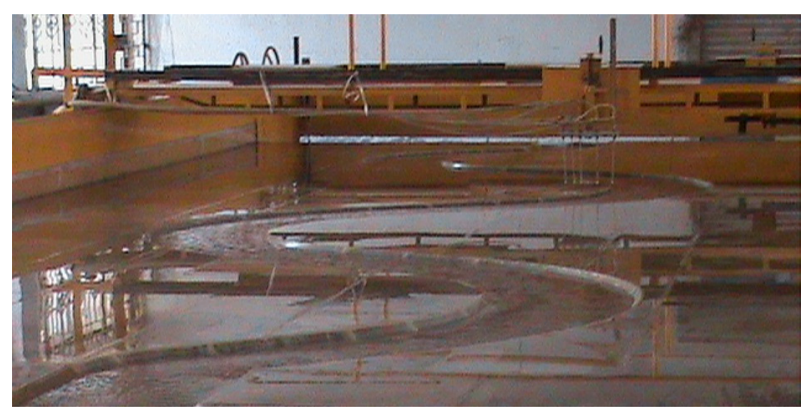

Photo 1: Details of meandering channel with the measuring equipments.

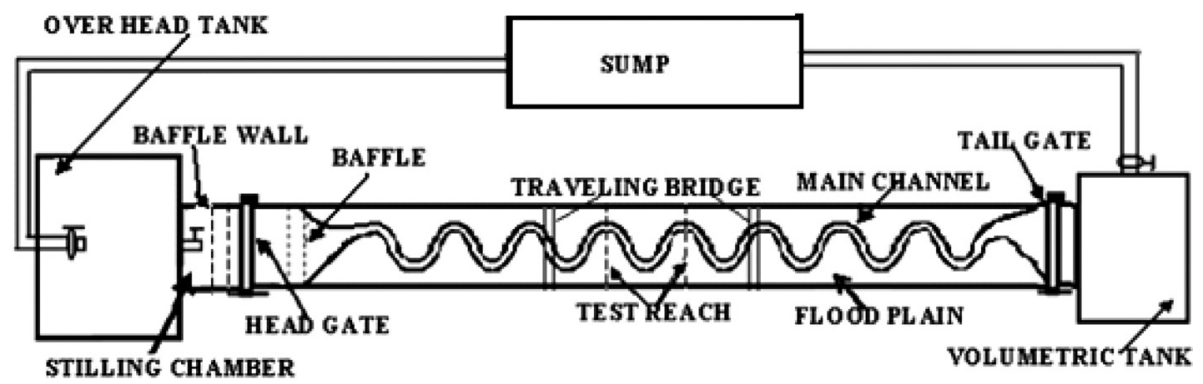

Figure 1: Water supply to meandering channel with measuring equipments. 
Table 1: Details of geometrical parameters of the experimental channels.

\begin{tabular}{lll}
\hline Item description & \multicolumn{2}{c}{ Present experimental channels } \\
\hline Channel type & Meandering channel (Type I) & Meandering channel (Type II) \\
Flume size & $4.0 \mathrm{~m} \times 15 \mathrm{~m} \times 0.5 \mathrm{~m}$ long & $4.0 \mathrm{~m} \times 15 \mathrm{~m} \times 0.5 \mathrm{~m}$ long \\
Geometry of channel section & Trapezoidal (side slope 1:1) & Trapezoidal (side slope 1:1) \\
Nature of surface of bed & Smooth and rigid bed & Smooth and rigid bed \\
Channel width & $33 \mathrm{~cm}$ at bottom and & $33 \mathrm{~cm}$ at bottom and $46 \mathrm{~cm}$ \\
& $46 \mathrm{~cm}$ at top & at top \\
Bank full depth of channel & $6.5 \mathrm{~cm}$ & $6.5 \mathrm{~cm}$ \\
Bed slope of the channel & 0.0022 & 0.0022 \\
Sinuosity & 1.12 & 1.25 \\
Amplitude & $951 \mathrm{~mm}$ & $1568 \mathrm{~mm}$ \\
Wave length in down valley & $3972 \mathrm{~mm}$ & $3944 \mathrm{~mm}$ \\
$\quad$ direction & & \\
\hline
\end{tabular}

At the top of the experimental flume, main guide rails are provided on which a traveling bridge is moved in the longitudinal direction of the entire experimental channel. The point gauge and five micro-Pitot tubes each having 4.6-mm external diameter are attached to the traveling bridge with secondary guide rails allowing the equipments to move in both longitudinal and the transverse directions of the experimental channel. Water surface slope measurement is carried out using a pointer gauge fitted to the traveling bridge. It is having least count of $0.1 \mathrm{~mm}$ and operated manually. Slopes of all meandering channels are obtained by dividing the level difference of channel bed and water surface between the two points by the length of meander wave along the centerline.

There are five Pitot tubes that are in conjunction with suitable five vertical manometers used to measure point velocity and its direction of flow at the predefined points of the flow-grid. The Pitot tube is physically rotated normal to the main stream direction till it gives maximum deflection of manometer reading. The angle of limb of Pitot tube with longitudinal direction of the channel was noted by the circular scale and pointer arrangements attached to the flow direction meter. A rectangular notch has also been fabricated and placed at the u/s face, which is calibrated to find the continuous stage-discharge relationships of the channels. Velocity measurements using these Pitot tubes are taken at the bend apex in meandering channel where minimum curvature effect is there. Actual discharges of the flow of water through the meandering channels were measured by the time rise method in the measuring tanks located at the downstream end of the experimental channel. All the observations are performed only under steady and uniform conditions. The geometrical parameters and hydraulic details of the experimental runs are given in Table 1.

\section{ANALYSIS OF EXPERIMENTAL RESULTS}

\subsection{Variation of Chezy's C}

The experimental results shown in Tables 2 and 3 belong to meandering channels Type I and Type II, respectively. The experiments are conducted in meandering channels of different sinuosities namely $S_{\mathrm{r}}=1.12$ corresponds to Type I and $S_{\mathrm{r}}=1.25$ corresponds to Type II channel. The experimental obser- 
Table 2: Details of experimental observations (Type I).

\begin{tabular}{lllll}
\hline Run no. & $Q\left(\mathrm{~m}^{3} / \mathrm{s}\right)$ & $H(\mathrm{~m})$ & $A\left(\mathrm{~m}^{2}\right)$ & $C$ \\
\hline MT1 & 0.0013 & 0.018 & 0.0063 & 58.809 \\
MT2 & 0.0016 & 0.019 & 0.0066 & 58.076 \\
MT3 & 0.0019 & 0.021 & 0.0072 & 56.033 \\
MT4 & 0.0023 & 0.024 & 0.0083 & 54.844 \\
MT5 & 0.0026 & 0.025 & 0.009 & 53.947 \\
MT6 & 0.0032 & 0.029 & 0.0104 & 51.214 \\
MT7 & 0.0041 & 0.034 & 0.0122 & 50.686 \\
MT8 & 0.0051 & 0.038 & 0.0141 & 49.047 \\
MT9 & 0.0056 & 0.041 & 0.0151 & 48.196 \\
MT10 & 0.0062 & 0.043 & 0.0162 & 47.867 \\
MT11 & 0.0064 & 0.044 & 0.0166 & 47.283 \\
MT12 & 0.0078 & 0.050 & 0.0190 & 46.282 \\
MT13 & 0.0085 & 0.053 & 0.0201 & 43.108 \\
MT14 & 0.0108 & 0.061 & 0.0239 & 36.451 \\
MT15 & 0.0110 & 0.062 & 0.0244 & 35.266 \\
MT16 & 0.0110 & 0.063 & 0.0247 & 35.183 \\
MT17 & 0.0118 & 0.065 & 0.0254 & 35.059 \\
\hline
\end{tabular}

Table 3: Details of experimental observations (Type II).

\begin{tabular}{lcccc}
\hline Run no. & $Q\left(\mathrm{~m}^{3} / \mathrm{s}\right)$ & $H(\mathrm{~m})$ & $A\left(\mathrm{~m}^{2}\right)$ & $C$ \\
\hline MT1 & 0.0014 & 0.016 & 0.0055 & 56.356 \\
MT2 & 0.0022 & 0.021 & 0.0073 & 55.286 \\
MT3 & 0.0032 & 0.027 & 0.0096 & 53.762 \\
MT4 & 0.0033 & 0.028 & 0.0100 & 52.963 \\
MT5 & 0.0039 & 0.031 & 0.0112 & 52.012 \\
MT6 & 0.0044 & 0.033 & 0.0120 & 51.554 \\
MT7 & 0.0052 & 0.037 & 0.0135 & 48.761 \\
MT8 & 0.0054 & 0.038 & 0.0138 & 48.319 \\
MT9 & 0.0064 & 0.042 & 0.0157 & 46.473 \\
MT10 & 0.0062 & 0.045 & 0.0155 & 45.629 \\
MT11 & 0.0082 & 0.050 & 0.0189 & 38.964 \\
MT12 & 0.0090 & 0.053 & 0.0201 & 37.257 \\
MT13 & 0.0093 & 0.054 & 0.0206 & 36.690 \\
MT14 & 0.0099 & 0.056 & 0.0216 & 35.614 \\
MT15 & 0.0103 & 0.057 & 0.0221 & 34.525 \\
MT16 & 0.0117 & 0.062 & 0.0243 & 33.914 \\
MT17 & 0.0124 & 0.063 & 0.0254 & 33.457 \\
MT18 & 0.0121 & 0.066 & 0.0251 & 32.400 \\
\hline
\end{tabular}




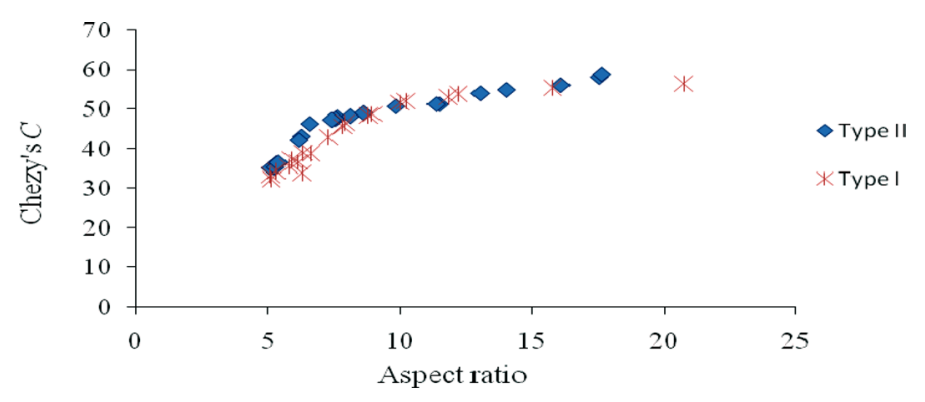

Figure 2: Variation in Chezy's $C$ with aspect ratio.

vations for both the meandering channels are recorded and presented here in Tables 2 and 3, respectively. Variation in Chezy's $C$ with depth of flow $(H)$ for these channels was investigated as shown in Fig. 2. The value of $C$ for both the experimental meandering channels exhibits an increasing trend with aspect ratio (ratio of width of the channel to the depth of flow). It confirmed that meandering channel losses more energy during its flow process. Variation in friction factor with a depth of flow $(\mathrm{H})$ for the same channels was also investigated, which has already been reported in Moharana et al. [17].

\section{MODEL DEVELOPMENT}

In this present work, an efficient technique such as ANFIS is proposed for the prediction of Chezy's $C$. An adaptive fuzzy system named as ANFIS stands for adaptive neuro fuzzy inference system. It is the combination of ANNs and fuzzy system [18]. Adaptive-network-based fuzzy inference system is a novel architecture that develops fuzzy if-then rules with suitable membership functions to have the required input-output pairs. This system is a fuzzy Sugeno by a forwarding network structure. This fuzzy model was first suggested systematically by Sugeno and Takagi [19]. This popular approach has been found in many practical applications including decision analysis, forecasting, operation management and control prediction system.

\subsection{ANFIS architecture}

The first-order Sugeno system optimizes the fuzzy system by using a hybrid learning rule. An example ANFIS system having two inputs $x$ and $y$ and one output is taken in this system. Its rule is given by Tashnehlab and Menhaj [20]

$$
\begin{aligned}
& \text { If } x \text { is the } A_{1} \text { and } y \text { is the } B_{1} \text {, then } f=p_{1} x+q_{1} y+r_{1} \\
& \text { If } x \text { is the } A_{2} \text { and } y \text { is the } B_{2} \text {, then } f=p_{2} x+q_{2} y+r_{2}
\end{aligned}
$$

where $C$ is the output and $p_{i}, q_{i}$ and $r_{i}$ are the consequent parameters of the $i$ th rule. $A_{i}$ and $B_{i}$ are the linguistic labels that are represented by fuzzy sets whose membership function parameters are premise parameters [21]. From ANFIS architecture, it is observed that the given values of the premise parameters and the overall output can be expressed as a linear combination of the consequent parameters. Basically, a fuzzy inference system is composed of five functional blocks as shown in Fig. 3. 


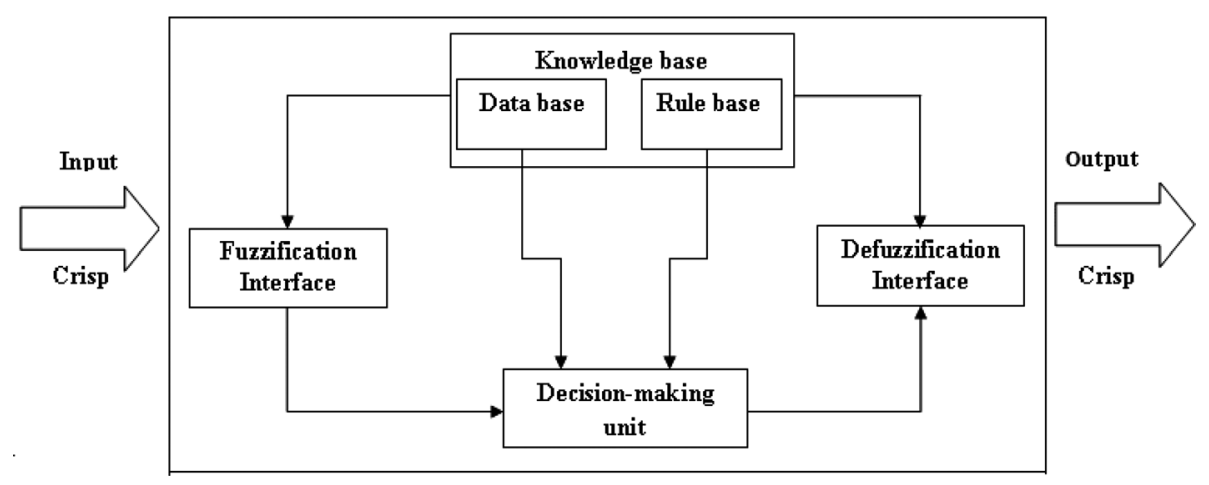

Figure 3: Block diagram of an ANFIS system.

\section{SOURCE OF DATA AND SELECTION OF PARAMETERS}

For simulation of discharge in meander river, a proper value of roughness coefficient is very essential. In the present study, taking different geometric and hydraulic conditions into our consideration the influencing non-dimensional parameters such as bed slope of the channel $(S)$, sinuosity $\left(S_{\mathrm{r}}\right)$, aspect ratio $(\alpha)$, Reynolds Number $(R e)$, roughness ratio $(\gamma)$ and side slope (tangent of angle $\theta$ with vertical) are taken as inputs for the model and roughness coefficient is taken as the output. Sinuosity $\left(S_{\mathrm{r}}\right)$ is the ratio of channel length to valley length, which refers to sinuous path of a channel. Aspect ratio $(a)$ is the ratio of the channel bottom width $(b)$ to flow depth $(h)$ in the channel. The data set was collected from several references such as Shiono et al. [3], Patra and Kar [4], Khatua et al. [7], Channel of Willets and Hardwick [22], Al-Romaih [23] and FCF channel [24]. Along with the present experimental results, some literatures are also reviewed and finally a data set is prepared as given in Table 4.

\section{RESULTS}

An equivalent ANFIS system is presented in Fig. 4a and a membership function used is given in Fig. 4b. In train epoch, the outputs of nodes (Fig. 4c) is calculated at the fourth layer, moving forward and then in next step moving backward, the ratio of error is propagated over the parameters based on error descent gradient method according to Rumelhart et al. [26]. In this section, to verify the accuracy of the results further regression analysis is also carried out. Regression curves are plotted showing the difference between actual Chezy's $C$ and predicted Chezy's $C$ through ANFIS model for training data and testing data, respectively. By using the testing data set, roughness value is calculated. It can be observed that the data are well fitted because a high degree of coefficient of determination $\left(R^{2}\right)$ as 0.913 for training (Fig. 5) and as 0.881 for testing data (Fig. 6) is obtained. Comparison of actual Chezy's $C$ and predicted Chezy's $C$ with different methods is shown in Fig. 7. From the regression analysis, it can be observed that ANFIS method showed maximum accuracy.

The performance of developed ANFIS model results for the training and testing phase is shown in Figs 7 and 8. Model results show a very good agreement with the actual results in predicting roughness values. As the predicted data pattern follows actual data with little or no exception, it demonstrates that the model predicts the pattern of the data distribution with adequate accuracy because a high degree of coefficient of determination is obtained for training and testing data. 


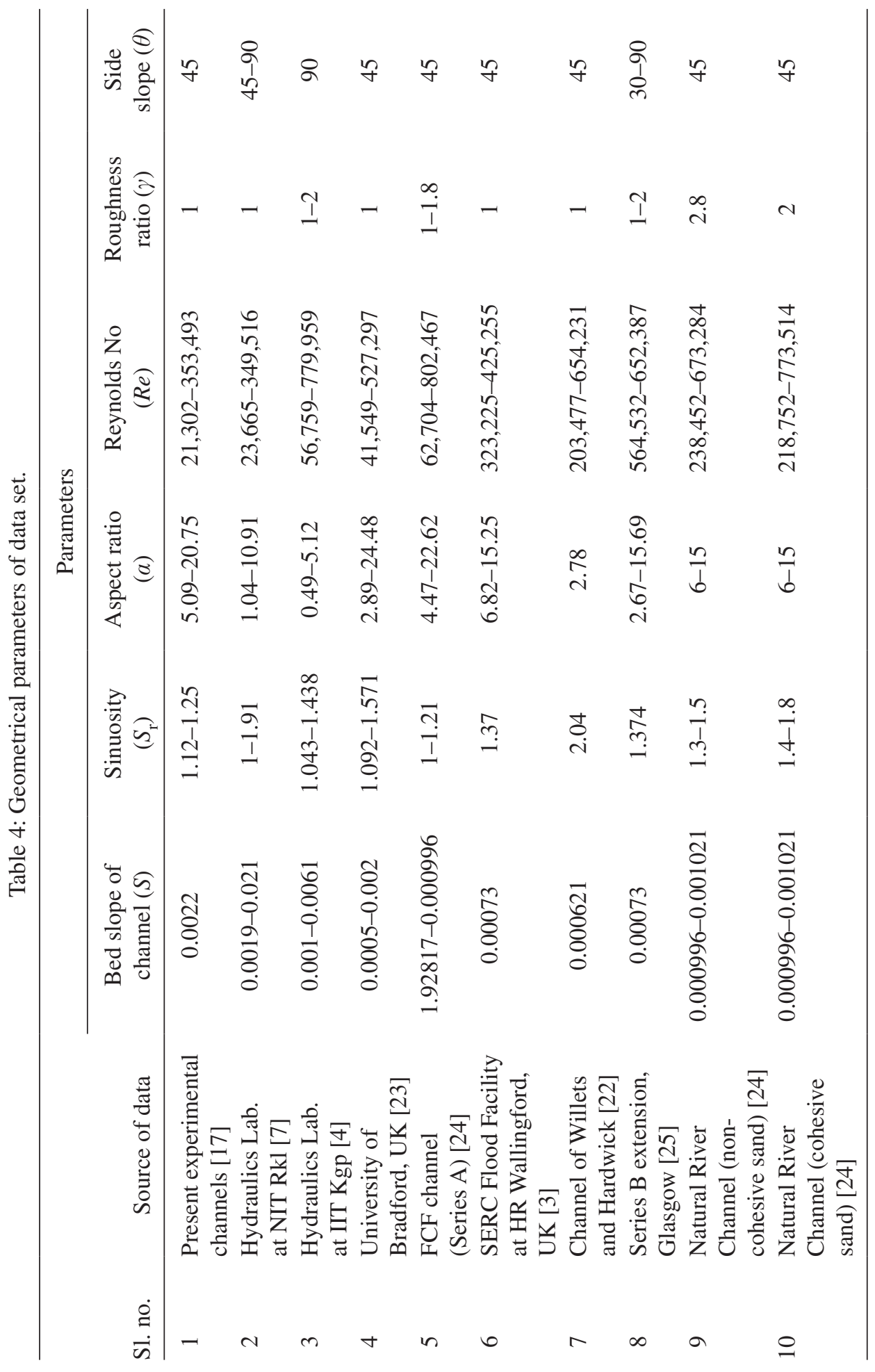




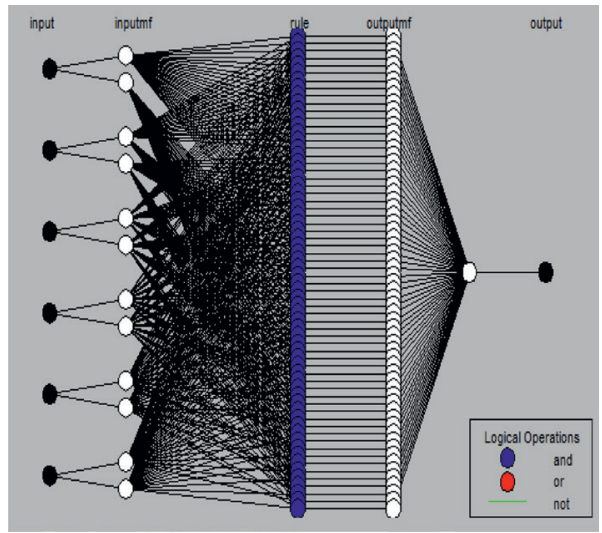

(a)

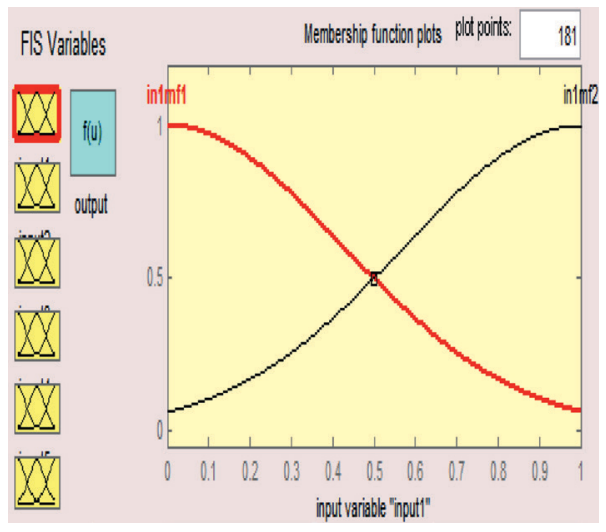

(b)

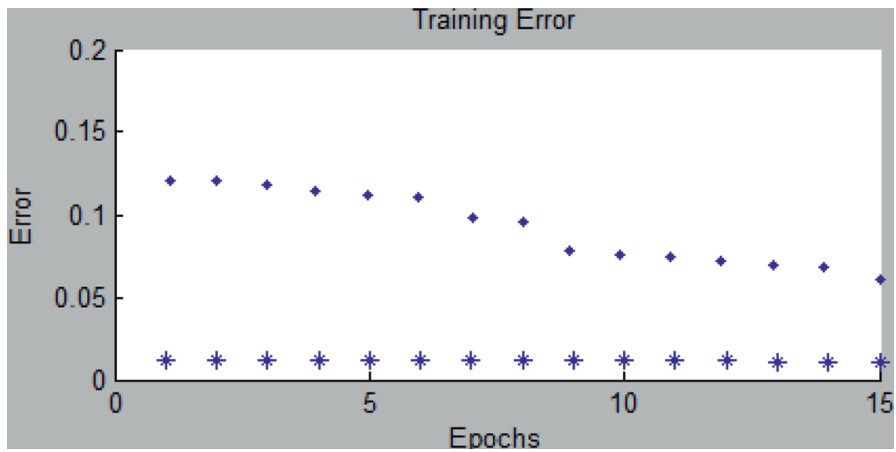

(c)

Figure 4: (a) Architecture of developed model; (b) membership function for ANFIS output; and (c) training error with epochs.

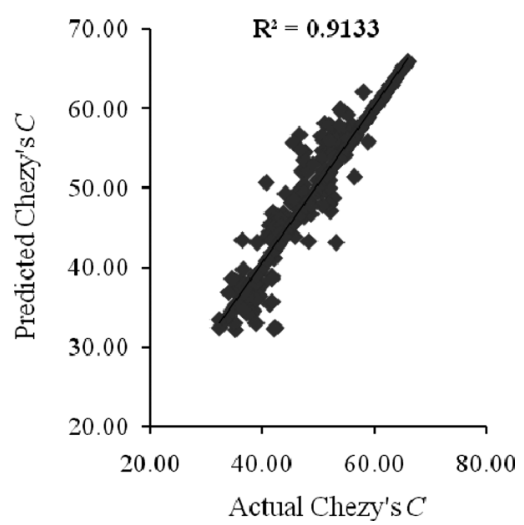

Figure 5: Distribution of training data. 


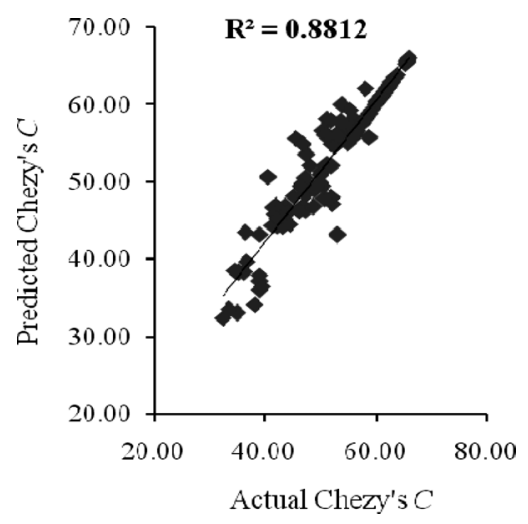

Figure 6: Distribution of testing data.

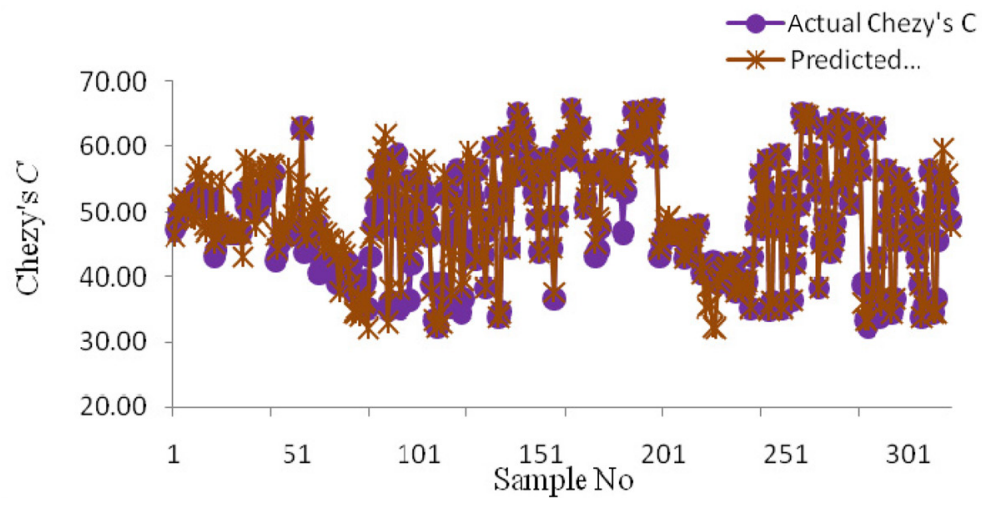

Figure 7: Matching figure of actual and ANFIS model results for $C$ in training step.

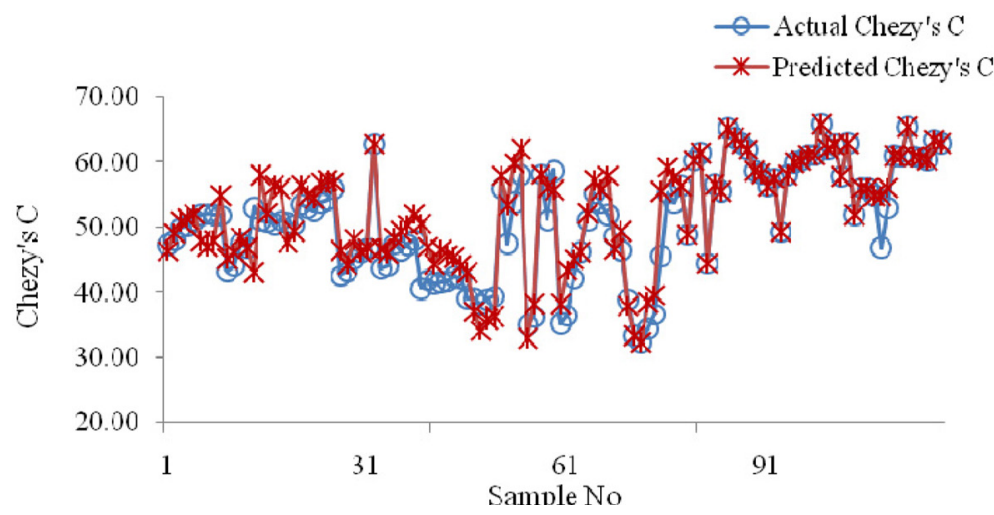

Figure 8: Matching figure of actual and ANFIS model results for $C$ in testing step. 


\section{DISCUSSION}

Roughness coefficient is calculated with appropriate hydraulic parameters using standard methods such as Shiono and Knight method (1999), Khatua et al. method (2011), LSCS method (1992), and comparison with ANFIS model is done by plotting the correlation plots. By using the testing data set, Chezy's $C$ value is calculated for different standard methods. Comparison of actual Chezy's $C$ with predicted Chezy's $C$ for different methods is shown in Fig. 9. In addition to this, to check the efficiency of the newly developed model different statistical analyses are conducted by the global data set. The results of statistical analysis are given in Table 5.

From Fig. 9, it is clear that Khatua et al. method (1999) gives good results showing coefficient of determination value 0.802 as compared with the other two established methods LSCS method (1992) and Shiono and Knight method (1999) having $\underline{\mathrm{R}}^{2} 0.742$ and 0.685, respectively. Here also ANFIS model shows good performance having the coefficient of determination value as 0.881 . From comparison of different methods, it is definitely concluded that ANFIS model shows very good results among all the existing methods for the prediction of roughness coefficients in terms of Chezy's $C$.

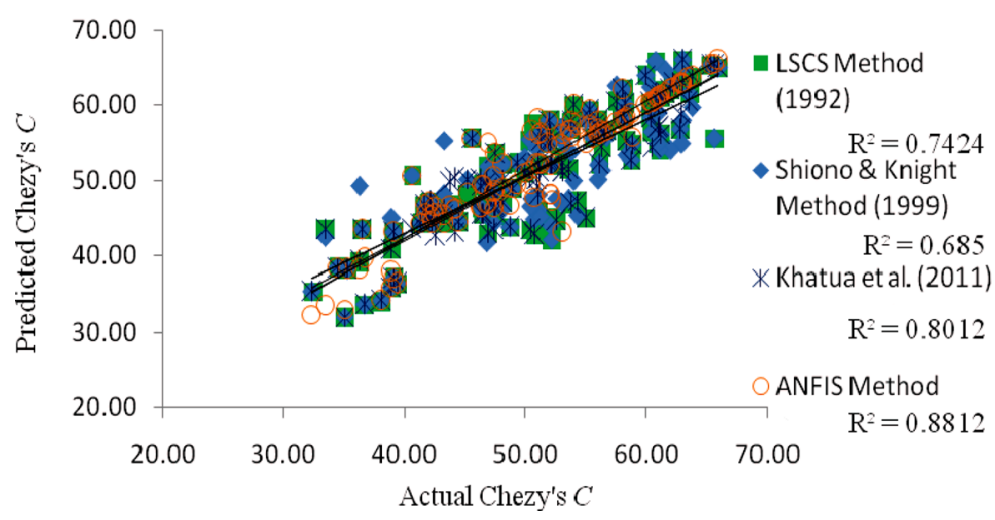

Figure 9: Comparison with different methods.

Table 5: Error analysis of different methods in prediction of $C$.

\begin{tabular}{lcccc}
\hline Methods & LSCS & & & \\
Statistical & $\begin{array}{c}\text { method } \\
\text { parameters }\end{array}$ & $\begin{array}{c}\text { Shiono and Knight } \\
\text { method (1999) }\end{array}$ & $\begin{array}{c}\text { Khatua } \text { et al. } \\
\text { method (2011) }\end{array}$ & $\begin{array}{c}\text { ANFIS } \\
\text { method }\end{array}$ \\
\hline MAE & 0.00783 & 0.00995 & 0.00648 & 0.00538 \\
MSE & 0.0000653 & 0.0000872 & 0.00003841 & 0.00002649 \\
RMSE & 0.008081 & 0.009338 & 0.006198 & 0.005147 \\
MAPE & 26.824 & 32.261 & 23.11 & 16.801 \\
$R^{2}$ & 0.742 & 0.685 & 0.802 & 0.881 \\
\hline
\end{tabular}




\section{CONCLUSIONS}

An experimental investigation was carried out to study the influence of sinuosity in determination of roughness coefficients of a meandering channel. An ANFIS approach is applied for proper estimation of roughness value in terms of Chezy's $C$ in a meandering channel. Different standard methods to predict the roughness coefficients of a meandering channel were also tested and verified with the laboratory findings and global data as well. The present ANFIS model performed better than other discussed methods. The reason may be that the traditional methods cannot establish nonlinear relationship between geometrical and hydraulic input parameters associated with roughness coefficients, whereas the ANFIS method could establish. Among the discussed methods, the Khatua et al. method (2011) and LSCS method (1992) overestimate roughness value, whereas Shiono and Knight method (1999) underestimates it. Statistical error analysis is carried out from which it is obvious that ANFIS model performed more accurately giving results by less error than different existing strategies. The analysis shows a high level of accuracy with regard to the ANFIS-based model developed for predicting the Chezy's $C$ especially coefficients of determination found to be 0.881 .

\section{ACKNOWLEDGEMENT}

We acknowledge the support from DST, Government of India granted to the second author for providing the necessary research facility to conduct experimentations in meandering channel.

\section{REFERENCES}

[1] Carter, R.W., Einstein, H.A., Hinds, Julian, Powell, R.W. \& Silberman, E., Friction factors in open channels, progress report of the task force on friction factors in open channels. Journal of the Hydraulics Division ASCE, HY2, pt.1, pp. 97-143, 1963.

[2] Sellin, R.H.J., A laboratory investigation into the interaction between flow in the channel of a river and that of its flood plain. La. Houille Blanche, No.7, pp. 793-801, 1964. doi: http:// dx.doi.org/10.1051/lhb/1964044

[3] Shiono, K., Al-Romaih, J.S. \& Knight, D.W., Stage-discharge assessment in compound meandering channels. Journal of Hydraulic Engineering, ASCE, 125(1), pp. 66-77, 1999. doi: http://dx.doi.org/10.1061/(asce)0733-9429(1999)125:1(66)

[4] Patra, K.C. \& Kar, S.K., Flow interaction of meandering river with floodplains. Journal of Hydraulic Engineering, ASCE, 126(8), pp. 593-604, 2000. doi: http://dx.doi.org/10.1061/ (asce) 0733-9429(2000)126:8(593)

[5] Khatua, K.K., Interaction of flow and estimation of discharge in two stage meandering compound channels. Thesis Presented to the National Institute of Technology, Rourkela, India, in partial fulfillments of the requirements for the Degree of Doctor of philosophy, 2008.

[6] Patra, K.C. \& Khatua, K.K., Energy loss and discharge estimation in two stage meandering and straight compound channel. EWRI of ASCE and IIT Kanpur, 2006.

[7] Khatua, K.K., Patra, K.C. \& Nayak, P., Meandering effect for evaluation of roughness coefficients in open channel flow. Sixth Int Conf on River Basin Management-VI, WIT Transactions on Ecology and the Environment (ISSN 1743-3541), pp. 213-227, Vol. 146, 2011. doi: http:// dx.doi.org/10.2495/rm110191

[8] Cowan, W.L., Estimating hydraulic roughness coefficients. Agricultural Engineering, 37, pp. 473-475, 1956.

[9] Acrement, G.J., Jr \& Schneider, V.R., Guide for selecting Manning's roughness coefficients for natural channels and flood plains. U.S. Geological Survey Water-Supply paper 2339, Federal Center, Colo, 1989. 
[10] U.S. Corps of Engineers, Hydraulic capacity of meandering channels in straight floodways. Tech. Memorandum No. 2-429, U.S. Army Corps of Engineers, Waterways Experiment Station, Vicksburg, Mississippi, 1956.

[11] James, C.S., Evaluation of methods for predicting bend loss in meandering channels. Journal of Hydraulics Engineering, ASCE, 120(2), pp. 245-253, 1994. doi: http://dx.doi.org/10.1061/ (asce)0733-9429(1994)120:2(245)

[12] Fasken, G.B., Guide for selecting roughness coefficient " $n$ " values for channels. Soil Conservation Service, U.S. Department of Agriculture, Washington, D.C., 1963.

[13] Parhi, P.K., Sankhua, R.N. \& Roy, G.P., Calibration of channel roughness for Mahanadi River, (India) using HEC-RAS model. Journal of Water Resource and Protection, 4, pp. 847-850, 2012. doi: http://dx.doi.org/10.4236/jwarp.2012.410098

[14] Hameed, L.K. \& Ali, S.T., Estimating of Manning's roughness coefficient for Hilla River through calibration using HEC-RAS model. Jordan Journal of Civil Engineering, 7(1), pp. 43-53, 2013.

[15] Maria, A.A. \& DaSilva, A.F., Friction factor of meandering flows. Journal of Hydraulic Engineering, ASCE, 125(7), pp. 779-783, 1999. doi: http://dx.doi.org/10.1061/(asce)07339429(1999)125:7(779)

[16] Folorunsho, J.O., Iguisi, E.O., Mu'azu, M.B. \& Garba, S., Application of adaptive neuro fuzzy inference system (ANFIS) in River Kaduna discharge forecasting. Research Journal of Applied Sciences, Engineering and Technology, 4(21), pp. 4275-4283, 2012.

[17] Moharana, S., Khatua, K.K. \& Sahu, M., Friction factor of a meandering open channel flow. River Basin Management VII, WIT Transactions on Ecology and the Environment, (ISSN 1743-3541), pp. 75-86, Vol. 172, 2013. doi: http://dx.doi.org/10.2495/rbm130071

[18] Jang, J.-S.R., ANFIS: adaptive-network-based fuzzy inference system. IEEE Transactions of Systems Man and Cybernetics, 23(3), pp. 665-685, 1993. doi: http://dx.doi. org/10.1109/21.256541

[19] Sugeno, M. \& Takagi, T., Fuzzy identification of systems and its applications to modeling and control. IEEE Transactions on Systems, Man and Cybernetics, Vol. SMC-15, No.1, pp. 116132, 1985. doi: http://dx.doi.org/10.1109/tsmc.1985.6313399

[20] Tashnehlab, M. \& Menhaj, S., Modeling trip tours using ANFIS modeling. Engineering Journal of Tehran University, 31, pp. 3361-3370, 2001.

[21] Werbos, P.J., Beyond regression: new tools for prediction and analysis in the behavioral sciences. PhD thesis, Harvard University, 1974

[22] Willetts, B.B. \& Hardwick, R.I., Stage dependency for overbank flow in meandering channels. Proceedings of the ICE - Water Maritime and Energy, 101, 1993. doi: http://dx.doi. org/10.1680/iwtme.1993.22989

[23] Al-Romaih, J.S., Stage discharge assessment in meandering channels. PhD thesis, University of Bradford, Bradford, U.K., 1996.

[24] http://www.birmingham.ac.uk

[25] http://theses.gla.ac.uk/1461/

[26] Rumelhart, D.E., Hinton, G.E. \& Williams, R.J., Learning representations by back-propagating errors. Nature, 323, pp. 533-536, 1986. doi: http://dx.doi.org/10.1038/323533a0 